\title{
Evaluation of an Environmental Impact Statement for the Environmental Impact Assessment Report for Modifications to the Petitcodiac River Causeway
}

\begin{abstract}
This paper is an evaluation of the environmental impact assessment report for the modifications to the Petitcodiac River Causeway. The environmental impact assessment (EIA) is an internationally utilized tool that is applied to inform decision makers of the environmental effects of industrial, commercial, and municipal undertakings (among other human activities); beyond this, EIAs provide a knowledge base for similar undertakings in the future. Using scholarly literature on the topic and regulatory framework references, this paper examines the expectation, reality, and divergence of three key themes in the given report with the aim of gauging its performance as an example of a modern ElA. Based on the report's commitment to monitoring and follow-up, cumulative effects assessment, and social impact assessment, the Environmental Impact Assessment Report for Modifications to the Petitcodiac River Causeway performs very strongly in light of academic criticisms of typical Canadian EIA practices.
\end{abstract}

\footnotetext{
About the Author(s): Davin St. Pierre holds a Bachelor of Arts and a Bachelor of Education from the University of New Brunswick. He is currently a candidate in the Masters of Resource and Environmental Management program at Dalhousie University where he concentrates his studies on material supply chains, waste management, and sustainable development. His keen interest in sustainable development has led him to pursue further academic research in the field.
} 


\section{Introduction}

Our world thrives and depends on industrialized development. These developments have the potential to degrade social well-being and usually tax Earth's resources while providing services and products for our modern society. To mitigate environmental degradation from these developments, we apply tools and frameworks to analyze potential environmental effects through evaluation, analysis, and monitoring programs. One such tool, ElA, is applied to limit the detrimental effects of various human activities and to provide a knowledge base for similar undertakings in the future.1 The Canadian Environmental Assessment Act, 2012 demonstrates how the EIA evolves and adapts in response to Canada's current economic and environmental context (CEAA, 2012a). Although evolving and subject to various economic and political stresses, the conservation of our environment depends on the concise and efficient application of EIAs. To highlight how a modern federal EIA evaluates the potential implications of a specific undertaking, this paper will assess three major themes produced in the EIA for the proposed modifications to the Petitcodiac River Causeway by AMEC Earth \& Environmental (2005). The three major themes that will be analyzed are:

- Commitment to monitoring and follow-up.

- Cumulative environmental effects assessment.

- Social impact assessment.

As a result of the long-term effects of human activity are having on ecosystems and communities, monitoring and follow-up programs, cumulative effects assessments, and social impact assessments are themes of growing importance within ElAs. I will evaluate AMEC's EIA report by comparing the above themes to relevant regulatory and academic literature.

In 1968, a causeway was built on the Petitcodiac River between the city of Moncton, New Brunswick, and the city of Riverview, New Brunswick. The structure was built to fulfill transportation needs of the region and to create a head pond. However, lack of foresight regarding the environmental effects of the structure brought about detrimental environmental impacts to the region and water system. Due to massive tides, sediment displacement, and diverse species in the Fundy Bay region,

\footnotetext{
${ }^{1}$ Human activities can include, but are not limited to industrial, commercial, and municipal projects.
}

2Especiallywhere baseline monitoring and quantitative data are considered vital Assessment Report for Modifications to the Petitcodiac River Causeway 
environmental effects quickly became apparent. As detailed in the Niles Report (2001), a preliminary report commissioned by the Minister of Fisheries and Oceans Canada prior to the in-depth EIA, fish passage issues with the causeway continued to be problematic and did not meet requirements under Section 20 of the Fisheries Act (AMEC, 2005). The EIA lists thirteen valued environmental components (VECs) that cover biophysical, social, and economic dimensions of four proposed project options. The four project options are:

1. Replacing the fishway

2. Opening gates during peak migration

3. Opening the gates permanently

4. Replacing causeway with partial bridge

4A. $170 \mathrm{~m}$ bridge downstream of causeway

4B. 280 m bridge downstream of causeway

4C. $315 \mathrm{~m}$ bridge central to the causeway

The Niles Report (2001) concludes that only options 3 and 4 meet the fishway requirements of Section 20 of the Fisheries Act, as well as other significant VEC requirements in the report. This conclusion led to the requirement of a full EIA for potential modification options.

\section{Theme Evaluation}

\section{Theme 1: Commitment to Monitoring and Follow-Up.}

\section{Expectation}

The monitoring and follow-up programs for the proposed undertakings seek to analyze the evolving effects that the project's options may have on its surroundings compared to its current state (i.e., the status quo of the Petitcodiac River Causeway and not the river's condition prior to installation in 1968). Defined by the International Association for Impact Assessment (Canter, 1999), follow-up and monitoring processes should ensure that terms and conditions of approval are met, monitor the effects of the development to determine whether mitigation measures are effective, and strengthen evaluation processes of future EIA applications for similar undertakings (Morrison-Saunders, et al., 2001). As per the Canadian Environmental Assessment Act of 2012, follow-up program requirements include a program to verify the accuracy of 
the environmental assessment and the effectiveness of the mitigation measures (CEAA, 2013). Scholars in the field of effective monitoring and follow-up place significant importance on the need for ElA analysts to set objectives that will provide evidence of the character and magnitude of environmental effects of human activity (Duinker, 1989). Process-based models (impact modeling and quantitative forecasting) that are supported by baseline monitoring and field experiments provide the strongest evidence of the character and magnitude of environmental effects of human activity (Duinker, 1989).

\section{Reality}

The follow-up program detailed in AMEC's EIA (AMEC, 2005) clearly states its compliance with the Report Guidelines (2002) and CEAA requirements (2013b). These guidelines and requirements form the basis of the program, which seeks to:

- Establish baseline conditions.

- Determine regulatory compliance (compliance monitoring).

- Test the predictions of the EIA Report (environmental effects monitoring) (AMEC, 2005).

- Evaluate the effectiveness of (mitigation) measures (AMEC, 2005).

The program is divided into a three-stage approach where all three stages pertain to monitoring strategies associated with the progression of the undertaking. The stages differ only slightly based on the four project options that are detailed above. It can be generalized that the follow-up program and monitoring strategies of all four options are similar.

Stage I of the monitoring and follow-up program is a collection of baseline data. This stage of the program involves either assembling data that are readily available from preliminary work (Niles, 2001; Locke, 2001), other municipal/provincial sources, or performing field experiments to obtain further data (AMEC, 2005). As this stage occurs prior to gate opening, a particular focus is set on baseline data sets pertaining to the effectiveness of the mitigation and construction activities of the project (e.g., former Moncton Landfill protection, upstream channel excavation, and upstream dyke restoration).

Stage II spans three years in order to develop follow-up data on the accuracy of hydrodynamic and sediment transport modeling predictions (AMEC, 2005). This stage 
of the project assesses the effectiveness of the planned mitigation strategies from monitored results and pursues adaptive management strategies if unknown or unforeseen results are reflected in the monitoring process. Stage III is a long-term follow-up of the physical characteristics of the Petitcodiac River estuary and will continue annually for three years after the project option is initiated. To evaluate the accuracy of long-term modeling predictions, follow-up will occur biannually for six years and again at twenty and thirty years (AMEC, 2005). Reports on all three stages of the follow-up program are provided on a monthly and bi-monthly basis in Stages I and II, respectively; annually for the first five years of Stage III; and once every three years, henceforth (AMEC, 2005).

\section{Divergence}

As this follow-up program utilizes baseline data derived from the status quo state of the river from a variety of sources and field research, it is fair to say that the program performs well (AMEC, 2005; Duinker, 1989).2 Generally, the three stages of the monitoring and follow-up program involve thorough process-based modeling, which includes impact models and quantitative forecasting according to the VECs of the given activity. In general terms, the follow-up and monitoring programs of this activity appear to meet the objectives set out in the Report Guidelines (NBDELG, 2002) and by the CEAA (CEAA, 2013b). Although this theme performs well based on the above analysis, there is, nonetheless, one area of potential concern.

Consultants have established that a three-year time span is sufficient between Stage II and Stage III for mitigation measures to be taken to limit erosion around the closed Moncton landfill site, as well as other river elements affected by erosion (AMEC, 2005). The Locke Report (2001), published by Fisheries and Oceans Canada, suggests that project options, other than the opening of the gates (Project options 2 and 3), will act as a catalyst for increased erosion of the closed landfill site and should be dealt with separately from discussions about the future of the causeway (Locke, 2001). It is a concern that, should Project Option 4 be selected between Stage II and Stage III, three years may not be sufficient time to assess, devise, and implement a plan of action to limit the leaching and erosion of the closed Moncton landfill site.

2 Especially where baseline monitoring and quantitative data are considered vital (prior to an intervention). 


\section{Theme 2: Cumulative Environmental Effects Assessment.}

\section{Expectation}

The International Association for Impact Assessment (IAIA) defines cumulative effects assessments (CEA) as "the need to address multiple actions representing potential sources of impact causing activities the consideration of multiple linkages (pathways) between such sources and receptors of impacts and, the recognition that such impacts may be additive, antagonistic or synergistic" (IAIA, 1999, "Cumulative Effects Assessment," para. 1).

According to the Canadian Environmental Assessment Agency (CEAA), the CEA calls for the consideration of any cumulative effects (e.g., biophysical, health, socioeconomic, physical, and cultural heritage effects), which are likely to result from a given project when it interacts with other existing or planned projects or activities (CEAA, 2012). The CEA Practitioners Guide (Hegmann et al., 1999) mandates that responsible authorities classify potential projects as certain, reasonably foreseeable, and hypothetical (CEAA, 2012). Classifications assist a practitioner in concentrating focus on projects that may have impacts on the same VECs as the project under assessment. It also assists by considering the effects of rapid development of the project area where particular environmental sensitivities or risks are involved (CEAA, 2012).

Academic discourse on the inclusion of CEAs in project-level EIAs is hardly supportive. Of the numerous issues that academics have revealed with CEA practice in EIAs, the most notable are:

- EIA focuses on project approval instead of environmental sustainability,

- a general lack of understanding of ecologic impact thresholds;

- separation of cumulative effects from project-specific impacts;

- weak interpretations of cumulative effects by practitioners and analysts; and

- inappropriate handling of potential future developments (Duinker \& Greig, 2005).

It would seem that the main critique of CEAs is that in our current framework they are subject to short-term, project-based pressures, when they should be primarily focused on long-term VEC sustainability. 


\section{Reality}

The cumulative environmental effects of the status quo and project options were evaluated with respect to four main categories of future actions: global, land use, economic, and cultural (AMEC, 2005). As the Guidelines (NBDELG, 2002) for this EIA do not provide a scope for the CEA to be conducted, the Practitioners Guide (Hegmann et. al., 1999) was adopted as the guiding document (AMEC, 2005). It was decided that the CEA would consider the measurable environmental effects of the status quo and project options acting in combination with predicted measurable effects of future actions relating to:

- biophysical VECs outside of the modeled river channel;

- the river channel itself (but not including changes to water quality); and

- socio-economic VECs (AMEC, 2005).

The CEA results of this EIA are unique in that the status quo state of the project was determined to contribute the most significant negative effects of all evaluated options (AMEC, 2005). Those negative status quo effects are:

- sedimentation and ice blocking outfall flap gates and drainage ditches downstream of the causeway;

- increased flooding of roads;

- sedimentation further reduces navigability;

- increased flooding resulting in property damage and increased insurance premiums;

- loss of opportunity for land and resource use for traditional purposes by the Aboriginal Community;

- loss of a natural estuary and the tidal bore and related tourism opportunity;

- loss of some recreational fisheries;

- loss or reduction of some commercial fisheries (e.g., American shad); and

- increased flooding risk, and public safety and human health risk due to recreational contact (AMEC, 2005). 
It was concluded that project options (AMEC, 2005) that met project objectives (fish passage in particular) would also benefit tidal exchange, and sediment transport, as well as other physical processes and biophysical functions (AMEC, 2005). No mitigation measures above and beyond what had already been outlined in the project options (AMEC, 2005) were detailed in the CEA, as they were deemed to be unnecessary even through to the year 2055 (AMEC, 2005).

\section{Divergence}

The CEA in this EIA can be seen as unique because the intervention is strongly predicted to have positive long-term effects on the majority of VECs that are being considered. Typically, one would expect that an undertaking would have negative effects on the environment. However, since the status quo state is the most harmful option, intervention seems logical (AMEC, 2005). With regards to how the CEA performs compared to the Practitioners Guide (Hegmann et. al., 1999), the CEA considered the effects of certain foreseeable and hypothetical projects in the future (AMEC, 2005). However, the majority of the research done in the EIA for cumulative effects is covered in the environmental effects research portions of the document. Therefore, further modeling was seen as unnecessary (AMEC, 2005).

Academic critique would lead one to believe that the inclusion of the CEA in this EIA process undermines the CEA's overall strength because of its (a) inability to address long-term effects in a short-term assessment, (b) EIA's focus on project approval, and (c) weak interpretations of cumulative effects and practitioners (Duinker \& Greig, 2005). Since the CEA is a mandatory component of the EIA (CEEA, 2013a), this EIA should not be discredited for following regulation. The objective-based models used in the environmental effects chapters of the EIA were used for CEA modeling and the focus of the cumulative effects on the VECs are based on long-term predictions (until 2055) (AMEC, 2005). This project is unique in that remediates negative effects from a prior development and allows for fairly accurate long-term predictions (based on a significant collection of data over a large period of time) (AMEC, 2005). In light of recent academic opinion, the CEA in this ElA reflects an exceptionally robust process.

\section{Theme 3: Social Impact Assessment}

\section{Expectation}

Social impact assessments (SIAs) are a rapidly evolving component of EIAs because of the understanding practitioners have developed around industry's inter- 
boundary effects on society and the environment. In a Canadian context, SIAs are typically represented as valued social components (VSCS) within VECs and, combined with the review of biophysical and environmental factors, have an equally important role in decision-making processes. The IAIA defines SIAs as the "process of assessing or estimating, in advance, the social consequences that are likely to follow from specific policy actions or project development" ("Social Impact Assessments", 2013, para. 1). Impacts that are recognized under typical SIA frameworks range drastically from aesthetic, cultural heritage, demographic, economic, gender, health, and impacts to indigenous rights, to infrastructural, institutional, leisure and tourism, political, and psychological themes. These themes can be summarized as impacts on social, sociocultural, economic, and biophysical surroundings (Vanclay, 2003) and these components are considered through the scoping processes of an EIA.

Social impacts are generally targeted using two different approaches in the scoping process: (a) technical and (b) participatory. The technical approach to SIAs is based on the expertise and knowledge of social scientists that direct the prediction of social impacts caused by planned interventions (Gomez et al., 2013). This approach is thought to be more objective and is largely based on quantifiable indicators to form expert opinions (Fenton, 2005). The second approach to the SIA process is based on public participation and stakeholder engagement. This approach can be summarized as one that fosters input from the local community's knowledge and understanding to predict potential social impacts of a proposed action that are contextually relevant to that community (Gomez et al., 2013). Both technical and participatory processes have shortcomings. Participatory SIAs tend to uncover "softer" impacts, which can be driven by passion, bias, and, in some cases, unjustifiable opinion (Gomez et al., 2013). Technical SIAs can misrepresent community concerns and risk the misconception of SIA practitioners as being infallible "experts" (Freudenberg, 1986). Modern best practice SIA scoping frameworks have moved towards an integrated approach because studies and research have shown an enhanced number of impacts identified, evaluated, and properly managed (using combined technical and participatory SIA processes) (Lane et al., 1997; Becker et al., 2004).

\section{Reality}

"Environmental Effect," as defined by the Project Guidelines (2002), includes typical environmental effects (on water, air, soil, plants, animals, etc.) as well as social, economic, cultural, and aesthetic conditions that influence the lives of humans or a community as they are related to other environmental factors (NBDELG, 2002). This means that VECs include social components in this EIA. From a regulatory standpoint, 
project guidelines were established through a harmonized federal/provincial ElA process, subject to review by a Technical Review Committee (TRC), government officials, and the public (NBDELG, 2002) (see Appendix A). To meet the requirements established in the Guidelines (2002), the Socio-Economic Component Study was undertaken by the AMEC Study Team. This study involved a wide variety of contributing professionals, including project managers, engineers, biologists, public consultation facilitators, biologists, modelers, ElA practitioners, economists, social scientists, and other contracted professionals (AMEC, 2005). The Socio-Economic Component Study also included significant input from public, stakeholder, and Aboriginal groups to further existing research done in the Locke Report (2001) in order to develop VSCs within the thirteen VECs selected in the study (AMEC, 2005). Ten of the thirteen VECs selected could be considered as VSCs:

- Atmospheric Environment;

- Fish and Fish Habitat;

- Terrestrial and Wetland Environment;

- Municipal Services and Infrastructure;

- Road Transportation Network;

- Vessel Traffic and Navigation;

- Land Use and Value;

- Current Use of Lands and Resources for Traditional Purposes;

- Tourism;

- Recreation;

- Labour and Economy;

- Heritage and Archaeological Resources; and

- Public Health and Safety (AMEC, 2005). 


\section{Divergence}

Existing baseline data (Locke, 2001), expert opinion, and government input, combined with public, community, and Aboriginal stakeholder consultations, were used in the SIA component of this EIA and show clear engagement (technical and participatory). In light of contemporary academic critiques, by avoiding an overreliance on any one forum of input, it seems that the proponent circumvented potentially biased community input (risks with solely participatory SIAs), as well as misrepresentative focus from experts (risks with solely technical SIAs) (Gomez et al., 2013). Although the focus of the given undertaking was to establish project options that addressed fish passage issues, as detailed in the Locke Report (2001), it had significant social ramifications. The scale of community input included in the SocioEconomic Component Study (AMEC, 2005) reflected sincere consideration for the variety of communities that can be affected by such a large alteration to a water system. In almost every way, the SIA component of this EIA reflects a successful and valuable example of a modern integrated SIA process.

\section{Conclusion}

As intervention, in this case, generally has positive effects on VECs (AMEC, 2005), this activity is more accurately described as a remediation project than an industrial undertaking. It is logical that positive effects on VECs lend to greater societal acceptance of an undertaking; however, the processes in which expert, government, public, and Aboriginal input were cultivated and incorporated should be commended. With respect to the three major themes that were evaluated, all three stood up as strong components of the EIA when compared to academic and regulatory expectations.

The state and quality of modern EIA practices can hardly be evaluated by analyzing three major themes in one individual EIA; however, in an era of critical academics and EIA practitioners, the Environmental Impact Assessment Report for the Modifications to the Petitcodiac River Causeway stands as a quality example of an EIA. Particularly where remediation undertakings are concerned, this EIA should be regarded as a guiding document for how effective modern EIAs should be conducted. As an EIA that met or exceeded regulatory, academic, and professional expectations, one can only hope that this EIA will be used as a case example for effective modern environmental management in our evolving industrial world. 


\section{References}

AMEC New Brunswick Department of Supply and Services. (2005). Environmental impact assessment report for modifications to the Petitcodiac river causeway (YB299A).

Becker, D., Harris, C., Nielsen, E., \& McLaughlin, W. (2004). A comparison of a technical and a participatory application of social impact assessment. Impact Assessment and Project Appraisal, 22 (3), 177-189.

Canadian Environmental Assessment Agency. (2012). Addressing cumulative environmental effects under the Canadian environmental assessment act: Background. Retrieved from: http://www.ceaaacee.gc.ca/default.asp?lang=En\&n=1F77F3C2-1

Canadian Environmental Assessment Agency. (2013a). Overview: Canadian Environmental Assessment Act, 2012. Retrieved from http://www.ceaaacee.gc.ca/default.asp?lang=en\& $n=16254939-1$

Canadian Environmental Assessment Agency (2013b). Policy and guidance: Former Canadian Environmental Assessment Act. Retrieved from http://www.ceaaacee.gc.ca/default.asp? lang=En\&n=F1F30EEF-1

Canter, L. (1999). Cumulative effects assessment. In J. Petts (Ed.), Environmental Impact Assessment: Process, Methods, and Potentia (Vol. 1, pp. 405-440). London, England: Blackwell Science.

Duinker, P. (1989). Ecological effects monitoring in environmental assessment: What can it accomplish? Environmental Management. 13(6), 797-805.

Duinker, P., \& Greig, L. (2005). The impotence of cumulative effects assessment in Canada: Ailments and ideas for redeployment. Environmental Management, $37(2), 153161$.

Fenton, M. (2005). Guidebook on social impact assessment, prepared for the Comprehensive Coastal Assessment. Environment and Behaviour Consultants, Townsville, Queensland. 
Freudenburg, W. (1986). Social Impact Assessment. Annual Review of Sociology, 12, 451-478.

Hegmann, G., Cocklin, C., Creasey, R., Dupuis, S., Kennedy, A., Kingsley, L., Ross, W., Spaling, H., Stalker, D. (1999). Cumulative effects assessment practitioners guide. Prepared by AXYS Environmental Consulting Ltd. and the CEA Working Group, Canadian Environmental Assessment Agency, Hull, Quebec.

International Association for Impact Assessment (2013). Multilingual Glossary: Social Impact Assessment. Retrieved from http://web2.concordia.ca/iaia/index.php?glossaryselect=\&beginswith=S\&PH PSESSID=a7f9aec2b739af60414f978c89222096

Lane, M., Ross, H., \& Dale, A. (1997). Social impact research: Integrating the technical, political, and planning paradigms. Human Organization, 56(3), 302-310.

Locke, A. (2001). Annotated bibliography of aquatic biology and habitat of the Petitcodiac River system. New Brunswick, Part 2. Can. Manuscr. Rep. Fish. Aquat. Sci. no. 2561.

Morrison-Saunders, A., Arts, J., \& Baker and P. Caldwell (2001). Roles and stakes in environmental impact assessment follow-up. Impact Assessment and Project Appraisal, 19, 289-296.

New Brunswick Department of Supply and Services. (2002). Guidelines for an environmental impact assessment: Modifications to the Petitcodiac river causeway. Department of the Environment and Local Government for the Province of New Brunswick and Fisheries and Oceans Canada, YB299A.

Niles, E. (2001). Review of the Petitcodiac river causeway and fish passage issues: Final report. New Brunswick: E.J. Niles \& Associates.

Vanclay F. (2003). Social impact assessment: International principles. International Association for Impact Assessment, Special Publication Series, 2. 